\title{
Application of Strong Sealing High-performance Water-based Drilling Fluid in the Horizontal Well of the Missan Oilfield
}

\author{
Lei Zhiyong, Chen Qiang, Guo Tao, Zhang Yong \\ China Oilfield Chemicals Services Limited, Tanggu, China \\ Email address: \\ leizhy@cosl.com.cn (Lei Zhiyong)

\section{To cite this article:} \\ Lei Zhiyong, Chen Qiang, Guo Tao, Zhang Yong. Application of Strong Sealing High-performance Water-based Drilling Fluid in the \\ Horizontal Well of the Missan Oilfield. American Journal of Engineering and Technology Management. Vol. 4, No. 6, 2019 , pp. 91-96. \\ doi: 10.11648/j.ajetm.20190406.13
}

Received: October 8, 2019; Accepted: November 15, 2019; Published: December 6, 2019

\begin{abstract}
In the Missan oilfield, because of its reservoir being "easy leakage in the up and low zones, and wellbore being collapse in the middle zone" with narrow density window, borehole instability, lost circulation, borehole collapse, sticking and other downhole complicated conditions were easily induced. A strong sealing and high performance water-based drilling fluid was mainly used to solve the problems of borehole instabilities in mud shale and muddy limestone in the horizontal wells of Missan Oilfield, for solving the problem of sidewall instability, aphysical/chemical plugging was used for strengthening the plugging of drilling fluid, improving the loading ability in formation, reducing the risk of lost circulation. The principle of "activity" regulation, permeable pressure were used to improve the semi-permeable membrane characteristics of mudstone and shale, reduce the activity of drilling fluid, inhibit the expansion ability of mudstone hydration and expansion in formation, on the basis of the static drilling fluid, permeable pressure was added to the wellbore for further improvement of borehole stability. The system in use reflects the stable rheological properties, it can be very good for plugging micro fractures, greatly improving the load ability in formation, the delaying time of borehole stability, guaranteeing the borehole stability in drilling, it provides support for the smooth drilling of the first horizontal well and consequent horizontal well drilling in Missan Oilfield.
\end{abstract}

Keywords: Water Based Drilling Fluid, Missan Oilfield in Iraq, Horizontal Well, Wellbore Stability, Chemical Plugging, Activity, Inhibition

\section{Background Introduction}

In in Iraq's Missan Oilfield, due to the complexity of limestone leakage and shale collapse in the reservoir section, the horizontal well operation in this block is unprecedented. In addition, the horizontal section drilled in this block is non-standard borehole. The minimum clearance between PD and borehole in $\Phi 8.25$ inch directional well section is only $1 / 16$ inch $(1.6 \mathrm{~mm})$, and the density window is narrow, which easily causes borehole instability and leads to downhole complications such as lost circulation, borehole collapse and sticking. Therefore, the main problem faced by drilling fluid for horizontal wells in Missan Oilfield is how to solve the problems of wellbore stability and leakage. however, the trend and characteristics of wellbore stability research are mainly unstable problems caused by geological factors, the interaction between shale and drilling fluid, drilling operations and other factors, i.e. wellbore stability, which is a very complicated worldwide problem encountered in drilling system engineering. Up to now, no complete and effective method has been developed to completely solve this problem [1-3]. The main causes of wellbore instability are: the liquid phase of drilling fluid enters the formation, causing the formation pore pressure to increase, and when the pressure difference between the drilling fluid pressure and the pore pressure is not sufficient to support the wellbore, the wellbore will become unstable (flaking or collapsing); water phase entering shale formation leads to hydration and dispersion of clay, which increases swelling pressure and leads to formation instability. Because the pressure transfer in shale is 1 2 orders 
of magnitude faster than solute and ion diffusion, and solute and ion diffusion is 1 2 orders of magnitude faster than drilling fluid filtrate; Therefore, the stabilization of borehole wall must be carried out simultaneously with the control of pressure infiltration to be effective.

Foreign drilling fluid companies had drilled many exploratory wells in the surrounding areas of Missan Oilfield, these wells have experienced many downhole complications such as out-of-control performance, borehole instability, sticking, lost circulation, overflow, etc. The author chose a strong plugging high-performance water-based drilling fluid system, which greatly improved the pressure bearing capacity of the borehole wall, avoided the risk of leakage, and increased the formation pressure bearing capacity by $0.15 \mathrm{~g} / \mathrm{cm}^{3}$. The system was successfully applied in BUCS-44H well, the first horizontal well in Iraq's Missan Oilfield, providing key technical guarantee for solving the problems of borehole wall instability, leakage and successful completion of the Iraq project.

\section{Geological Characteristics and Countermeasures of Reservoirs in Missan Oilfield}

In the missan oilfield, the formation lithology of the $\Phi 8.25$ inch interval has the characteristics of" upper and lower leakage and middle collapse", malignant irreversible leakage is easy to occur in the upper part, the collapse pressure in the middle part is high and sticking is easy to occur due to collapse, the next formation is the main oil layer. Limestone formation is developed in the pores and well leakage is easy to occur [4-7]. The traditional plugging materials such as fruit shells and mica lack plugging materials with strong porosity, which have poor pressure bearing capacity, and the plugging balance is easy to be damaged during drilling [8-10]. After plugging, fractured leakage changes into permeable leakage, and permeable leakage changes into fractured leakage, which is easy to generate vicious cycle (see Table 1 for formation distribution).

Table 1. Formation analysis of the $\Phi 8.25$ inch interval.

\begin{tabular}{lll}
\hline Formation & Lithological description & Risk alert \\
\hline Jeribe/Euphrates & dolomite dominated & - \\
Upper kirkuk & Sandstone and black brown shale are not interbedded with limestone and thin dolomite. \\
M-L kirkuk & Sandstone and Black Brown Shale Interbedded & leakage \\
Jaddala & - & leakage and collapse \\
Aaliji & - & leakage \\
Shiranish & Clay bright white limestone & Shrinkage and collapse \\
Hartha & Pore-developed limestone & leakage \\
Sadi & Clay bright white limestone & Easy to collapse \\
Tanuma & Top: malr; middle: thin limestone; lower: longer shale & Easy to collapse \\
Khasib & White limestone & - \\
Mishrif & Pore-developed limestone and dense limestone & leakage \\
\hline
\end{tabular}

\section{Difficults and Countermeasures for Drilling Fluid}

\subsection{Major Difficults for Drilling Fluid}

1) Leakage prevention in Kirkuk horizon: Downhole leakage has occurred in the drilled Kirkuk horizon. In case of leakage, it is easy to cause complicated leakage with no return. Leakage prevention shall be the main method to improve the pressure bearing capacity of the formation.

2) Anti-collapse of TANUMA horizon: shale collapse of borehole wall has occurred in the drilled Tanuma horizon, which is easy to cause hard sticking, it is necessary to prevent borehole wall collapse during drilling.

3) Leakage prevention work in MISHRIF horizon: landing in mishrif horizon, with high density in the hole bottom, limestone fractures are prone to leakage. in case of irreversible leakage, it is bound to affect the smooth landing of the project, and the lowering of drilling fluid column pressure may cause the collapse of upper TANUMA horizon.
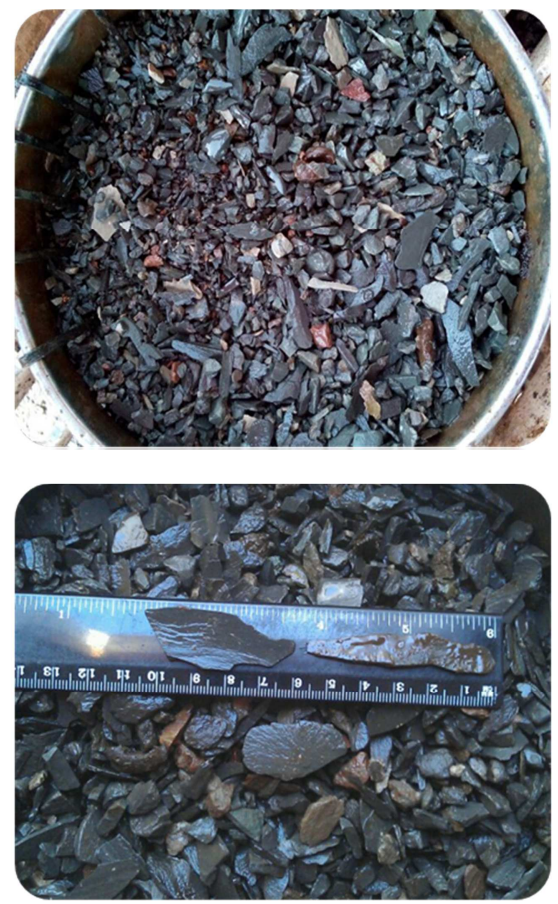

Figure 1. Cuttings falling from straight section of 8 1/4"well section drilled earlier. 
In the Missan oilfield, the most important problem of horizontal wells is how to solve the problem of borehole wall, to solve the problem of borehole wall instability, starting with drilling fluid, the following countermeasures should be taken.

\subsection{Wellbore Stability's Measures}

\subsubsection{Maintain Proper Density of Drilling Fluid}

If the drilling fluid does not have proper density, no matter what drilling fluid system is used, it may lead to wellbore instability; due to the complexity of the formation, the oilfield is prone to leakage when the density is high and collapse when the density is low, so it is necessary to improve the formation pressure bearing capacity by improving the plugging property of drilling fluid [11-15].

\subsubsection{Improve the Efficiency of Shale Permeable Membrane}

Improve the efficiency of shale permeable membrane, reduce the water activity of drilling fluid, and generate pore water flowing from shale to drilling fluid, thus reducing the water content and pore pressure of shale near the borehole wall; The system improves the efficiency of shale permeable membrane through physical-chemical plugging, so as to well seal the formation, prevent the invasion of filtrate, improve the pressure bearing capacity of the formation and prolong the stability time of the borehole wall.

\section{Key Technical Measures}

\subsection{Strong Sealing High-performance Water-based Drilling Fluid}

Strong plugging high-performance water-based drilling fluid is mainly used to solve the problems of wellbore instability and limestone leakage of shale and marl faced by horizontal wells in Missan Oilfield. Physical/chemical synergistic plugging is adopted to strengthen the plugging property of drilling fluid, improve formation pressure bearing capacity and reduce leakage risk. The principle of "activity" regulation and osmotic pressure is adopted to improve the semi-permeable membrane characteristics of mud and shale, reduce the activity of drilling fluid, and inhibit the hydration and expansion capability of mudstone in the formation, so that the borehole wall increases osmotic pressure on the basis of the static pressure of drilling fluid and further improves the stability of the borehole. At the same time, stable rheology should be combined to ensure the stability of the borehole during drilling.

Basic formula of drilling fluid: 1.5\% 2\% pre-hydrated bentonite slurry+ $0.3 \% \sim 0.8 \%$ costic soda $+0.2 \% \sim 0.4 \%$ soda ash $+0.3 \% \sim 0.5 \%$ HI-VIS $+1.5 \% \sim 3 \%$ starch $+(10 \% \sim$ saturated $)$ composite salt $+1.5 \% \sim 2 \%$ asphalt $+\quad 1 \% \sim 2 \%$ physical plugging agent $+1 \% \sim 2 \%$ Chemical plugging agent $+0-1.5 \%$ plugging agent while drilling $+0-3 \%$ inhibitory polyalcohol $+0 \sim 3 \%$ Salt-resistant lubricant; Barite was used to adjust the density to $1.28 \mathrm{~g} / \mathrm{cm}^{3}$. The test of its basic performance is shown in Table 2. The rheological property of the strong plugging high-performance water-based drilling fluid is stable, with the properties of low viscosity and high shear, and the water loss is small. This shows that the drilling fluid can form effective mud cake and prevent the filtrate from entering. The mud cake lubrication coefficient is only 0.11 , which basically can reach the level of oil-based drilling fluid. The system performance can fully meet the requirements of horizontal well operation.

Table 2. Basic properties of drilling fluid.

\begin{tabular}{|c|c|c|c|c|c|c|c|c|c|}
\hline Testing condition & AV/mPa. s & PV/mPa. s & $\mathbf{Y P} / \mathbf{P a}$ & Ф6/Ф3 & GEL (Pa/Pa) & FL/mL & HTHP $120^{\circ} \mathrm{C} / \mathrm{mL}$ & $\begin{array}{l}\text { lubrication } \\
\text { coefficient }\end{array}$ & pH \\
\hline BR (Before Rolling) & 50.5 & 39 & 11.5 & $7 / 6$ & $3 / 4.5$ & 2.6 & - & - & 11 \\
\hline AF (After Rolling) & 48 & 36 & 12 & $6 / 5$ & $2.5 / 4$ & 2.8 & 6.4 & 0.11 & 9.5 \\
\hline
\end{tabular}

Hot rolling: $120^{\circ} \mathrm{C} \times 16 \mathrm{~h}$; HPHT filtration test: $120^{\circ} \mathrm{C} \times 3.5 \mathrm{MPa}$.

\subsection{Physical-chemical Cooperstive Plugging}
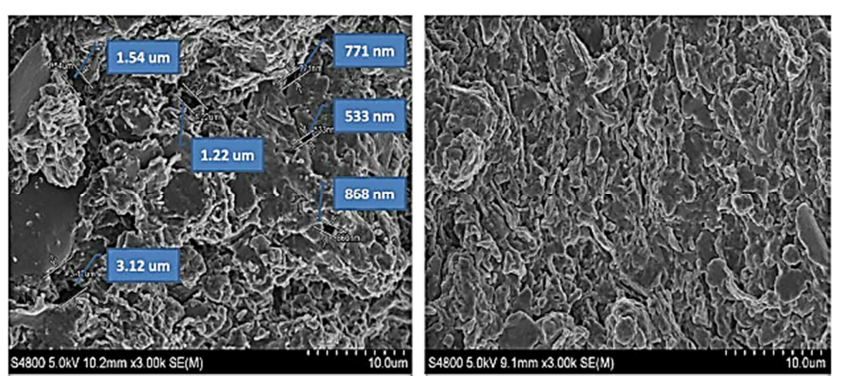

Figure 2. Scanning effect of physical-chemical synergistic blocking electron microscope (x 3000 times).

The combination of physical plugging agent and chemical plugging agent produced by independent invention is introduced to improve the plugging property of drilling fluid, which can effectively plug pore throats and microcracks to achieve strong plugging effect (see Figure 2). Meanwhile, due to the unique characteristics of chemical plugging agent, it can give full play to its characteristics in the system and the drilling fluid performance regulation becomes more "intelligent".

\subsubsection{Physical Plugging}

PF-GREENSEAL (physical plugging agent) is a white solid particle that is easy to disperse in water. It is a micron-sized non-deformable material and a nano-sized deformable detachable plugging polymer. The nano-sized particle size distribution is uniform, which can plug micro-pores and deform into micro-fractures, reduce pore pressure transmission, is stable in a high salinity environment, and can be matched with conventional plugging materials to better seal the formation. Blocking mechanism: under the action of 
positive pressure difference, it quickly enters the near-wellbore zone to form a dense isolation layer zone (inner mud cake), deforming to block micro-fractures and pore throats, slowing down pressure transmission, reducing filtrate penetration and prolonging wellbore stability time.

\subsubsection{Chemical Plugging}

The chemical plugging agent is a black-brown flaky solid, aluminum salt sulfonated organic polymer complex. It can cooperate with matched physical plugging agent to more effectively improve semi-permeable membrane efficiency, reduce shale permeability and slow down pore pressure transmission speed; $10<\mathrm{pH}<12$, it mainly exists in the form of $\left[\mathrm{Al}(\mathrm{OH})_{4}\right]^{-}, 5<\mathrm{pH}<8$, it forms $\mathrm{Al}(\mathrm{OH})_{3}$ precipitate. Figure 4 is a schematic diagram of "inner mud cake" formed by PF-CHEMSEAL in PIERRE II shale. from the diagram, it can be seen visually that the physical plugging agent can effectively plug mud shale.

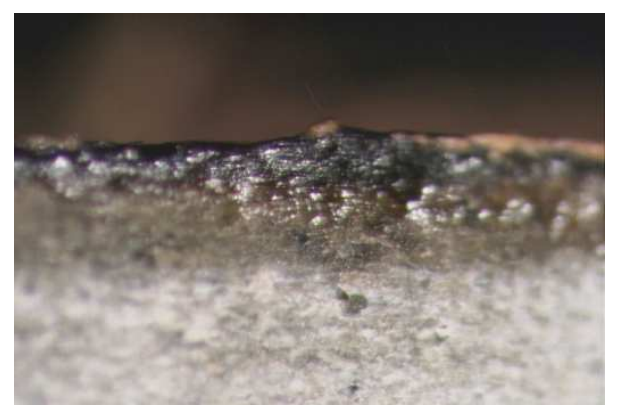

Figure 3. "Inner mud cake" formed by pf-chemseal in PIERRE II shale.

\section{Field Maintenance and Application Effect}

\subsection{Key Technical Measures for Field Drilling Fluids}

1) When start drilling, maintain the drilling fluid content at $20-25 \mathrm{~kg} / \mathrm{m}^{3}$ to ensure wall-building property; The funnel viscosity during drilling should be within $60 \mathrm{~s} \sim 70 \mathrm{~s}$, if it is too low, the borehole wall will be scoured greatly and a small amount of chips will fall off.

2) During the field application of the system, the $\mathrm{pH}$ consumed by the drilling fluid is relatively high, and the $\mathrm{pH}$ has a great influence on the viscosity of the drilling fluid. The viscosity can be controlled by controlling the $\mathrm{pH}$. Because PF-VIS is too sensitive to the $\mathrm{pH}$, if the $\mathrm{pH}$ is too high, the system structure will be destroyed, the viscosity of the drilling fluid will plummet, and the suspension capacity will be lost. If the $\mathrm{pH}$ is too low, PF-CHEMSEAL will be screened out in solid phase, therefore, caustic soda water should be added in time to maintain the $\mathrm{pH}$ of the drilling fluid at 9 10.

3) PF-GREENSEAL, PF-CHEMSEAL and compound salt are used in combination to improve formation pressure bearing capacity, and timely supplement the dosage of each plugging material. If there is still more shale or limestone flaking during drilling, the amount of
PF-GREENSEAL can be appropriately increased while maintaining the asphalt content.

4) When drilling to UPPER KIRKUK, there are thin layers of sandstone, especially the sandstone of BU formation, which is about $100 \mathrm{~m}$ thick, so the sand and mud remover can be used in advance (especially the mud remover has better effect), otherwise the proportion will increase rapidly. Do not use centrifuges as far as possible, centrifuges cause too much material loss and will reduce the effective content.

5) When drilling to the directional well section, timely supplement lubricant dosage, and use PF-BLA B (plastic pellets) and PF-GRA (elasticity graphite) in combination. Ensure lubricity of drilling fluid and reduce abrasion resistance. If there is a phenomenon of pressure, can be half an hour 1 bag of plastic balls to prevent a phenomenon of pressure; Plastic pellets can be added in the amount of $1 \%$ of the sealing slurry before running casing, and the contents of PF-JLX C (polyol) and lubricant are increased by $2 \%$ respectively.

6) Detect density and return status in time, if there is a block drop, the specific gravity can be appropriately increased and controlled to prevent borehole wall collapse caused by too low specific gravity, and leakage caused by too high specific gravity. At the same time, maintain the viscosity for about $65 \mathrm{~s}$, reduce the scouring effect on borehole wall, and prevent formation of cuttings bed, especially in the 40 60 deviation interval. The specific gravity is maintained below $1.27 \mathrm{~g} / \mathrm{cm}^{3}$ in straight section drilling.

7) During the long-term lifting process, it is necessary to increase the specific gravity of the drilling fluid and maintain the hydrostatic injection pressure in the wellbore to prevent collapse caused by pressure release, which is generally $0.02 \mathrm{~g} / \mathrm{cm}^{3}$ higher than drilling. After the drilling is completed, the mud remover shall be used to throw it to the original specific gravity, after passing through TAMUMA formation, the specific gravity gradually increases to $1.30 \sim 1.32 \mathrm{~g} / \mathrm{cm}^{3}$, and gradually increases to $1.35 \sim 1.37 \mathrm{~g} / \mathrm{cm}^{3}$ after completion of drilling and during the well passage to ensure smooth well passage. it is recommended to supplement PF-SZDL material appropriately before increasing the specific gravity.

\subsection{Application Effect}

\subsubsection{Good Rheolegical Properties}

In the process of drilling the reservoir section of Missan Oilfield, the high-performance water-based drilling fluid has stable performance, simple maintenance and treatment, smooth pump start-up circulation, and achieves the purpose of safe and rapid drilling. Take Well BUCS-XXH as an example (Table 3), the rheological property of drilling fluid is stable from the time of entering the well until the completion of drilling. 
Table 3. Rheological properties of drilling fluids in $\Phi 8.25$ inch section of BUCS-XXH Well.

\begin{tabular}{|c|c|c|c|c|c|c|c|c|c|}
\hline depth/m & $\mathbf{F V} / \mathbf{s}$ & $\mathrm{MWg} / \mathrm{cm}^{3}$ & AV/mPa. s & PV/mPa. s & $\mathbf{Y P} / \mathbf{P a}$ & $\Phi 6 / \Phi 3$ & GELPa/Pa & FL/mL & $\mathrm{pH}$ \\
\hline 2832 & 58 & 1.23 & 38 & 27 & 11 & $5 / 4$ & $2 / 3.5$ & 1.8 & 11 \\
\hline 2852 & 48 & 1.23 & 31.5 & 23 & 8.5 & $4 / 3$ & $1.5 / 3.5$ & 2.4 & 11 \\
\hline 2860 & 54 & 1.23 & 35 & 26 & 9 & $5 / 4$ & $1.5 / 3.5$ & 2.2 & 10 \\
\hline 2872 & 58 & 1.24 & 37 & 27 & 10 & $5 / 4$ & $1.5 / 3.5$ & 1.8 & 9.5 \\
\hline 2912 & 61 & 1.25 & 39 & 28 & 11 & $6 / 4$ & $2 / 4.5$ & 1.6 & 9 \\
\hline 3051 & 65 & 1.25 & 44.5 & 30 & 14.5 & $6 / 4$ & $2 / 3.5$ & 1.8 & 8.5 \\
\hline 3102 & 63 & 1.26 & 44 & 30 & 14 & $6 / 4$ & $2 / 3.5$ & 1.8 & 9 \\
\hline 3525 & 66 & 1.28 & 49 & 34 & 15 & $6 / 4$ & $2 / 3.5$ & 1.2 & 8 \\
\hline 3894 & 64 & 1.31 & 47.5 & 37 & 10.5 & $5 / 4$ & $2 / 3.5$ & 0.7 & 8.5 \\
\hline 4083 & 65 & 1.36 & 46 & 35 & 11 & $6 / 5$ & $2.5 / 3.5$ & 0.6 & 9 \\
\hline
\end{tabular}

\subsubsection{Excellent Lubrication Performance}

To maintain good lubrication performance of drilling fluid. At present, the viscosity coefficient instrument is used to monitor the lubricity of drilling fluid on-site, which ensures the friction coefficient below 0.10 and meets the requirements of field operation. Before drilling through MB1, increase the volume of circulating pool PF-JLX-C to $30 \mathrm{~kg} / \mathrm{m}^{3}$. Drill to the directional interval and use PF-BLA B and PF-GRA, and gradually increase the salt-resistant lubricant content to $2 \%$ to ensure the lubricity of drilling fluid and reduce wear resistance.

\subsubsection{Unique "Liquid Casing" Function}

The rheological property of drilling fluid is stable and easy to adjust during drilling, which is due to the addition of two "intelligent" plugging agents into the drilling fluid system, which can give full play to its characteristics in the system and make the performance adjustment of drilling fluid more "intelligent". Due to the use of two plugging agents and the lack of free water in the drilling fluid, the drilling fluid has an obvious gel phenomenon of "high temperature $\left(50^{\circ} \mathrm{C}\right)$ dilution and low temperature thickening": during the long-term drilling process, due to the lower temperature, it has a stabilizing effect on the borehole wall, and during the drilling process, the structure will be destroyed, the temperature will be increased, and the drilling fluid will restore its good rheological properties, this has a certain protective effect on the borehole wall and acts as a "liquid casing".

\subsubsection{Strong Plugging and Stable Borehole}

The $\Phi 8.25$ inch interval uses a high-performance water-based drilling fluid system, and the site uses a non-permeable visual filter to detect the plugging property of the drilling fluid in time, the test results show that the drilling fluid has zero water loss, which is sufficient to prove that the drilling fluid can quickly form a good" internal mud cake", which plays a strong plugging role, prevents filtrate entering the formation, and thus also plays a role in preventing collapse.

For vertical wells with the same well depth, the operation cycle is basically the same, and the drilling fluid is not consumed much during the operation of horizontal wells, but the vertical section of horizontal well has no big belly and the well diameter is more regular, which indicates that the drilling fluid has extremely strong plugging property. The two "intelligent" plugging agents can well seal the formation, play a certain role in strengthening the borehole wall and improve the bearing capacity of the borehole wall. In the measurable vertical well section, there is no any sticking phenomenon in tripping out and tripping in the layer prone to collapse and leakage, tripping out and tripping in are smooth, electrical logging is smooth, well diameter is regular (figure 4 is the comparison curve of well diameter between horizontal well BUCS-XXH and 8-1/4 "vertical well section of vertical well FQ-XX drilled earlier), the borehole is stable, the bottom of the well is free of sand deposition, casing running and cementing operations went smoothly, the downhole safety is ensured, and a solid foundation is laid for the next reservoir opening operation.

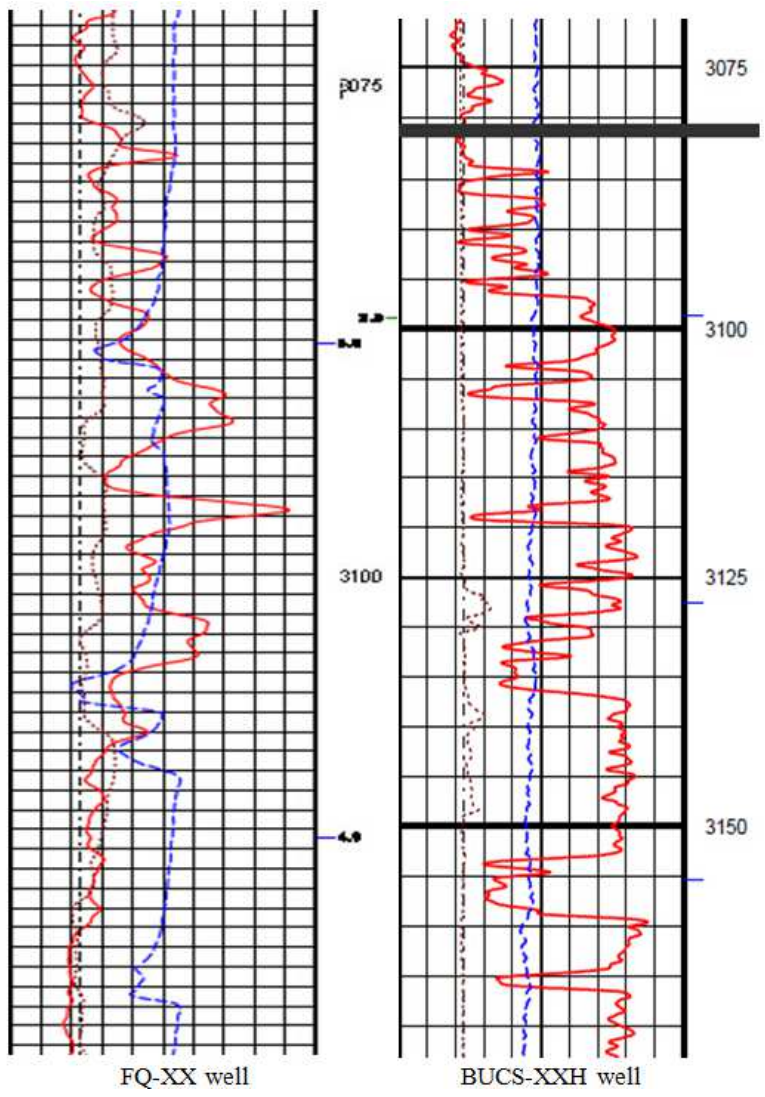

Figure 4. Comparison of well diameters of $\Phi 8.25$ inch interval between $F Q-X X$ and well BUCS-XXH. 


\section{Conclusions}

1) Strong plugging high-performance water-based drilling fluid shows stable rheological property and excellent comprehensive performance, many performance indexes are close to that of oil-based drilling fluid, and the lubrication coefficient can be reduced to 0.10 , at the same time, it shows unique "liquid casing" function and can fully meet the requirements of horizontal well operation in the Missan oilfield.

2) The drilling fluid adopts the principle of compound salt "activity" regulation and osmotic pressure, i mproving the characteristics of shale semi-permeable membrane, inhibit the hydration expansion of mudstone in formation and further improve the stability of borehole.

3) The drilling fluid adopts physical-chemical synergistic plugging, which can well plug formation microfractures, greatly improve formation pressure bearing capacity, delay wellbore stability time, ensure wellbore stability during drilling, and provide good guarantee for subsequent horizontal well development in the Missan oilfield.

4) The smooth completion of horizontal well drilling in the Missan oilfield has provided valuable successful experience for complicated horizontal well operations, unconventional well operations prone to leakage and collapse, and slim hole operations in Iraq and even more in the Middle East. It is a rare basis and reference and is of great significance to the development of Missan oilfield.

\section{References}

[1] Zhang Yikai; Kang An; Min Xiaogang; et al. Charateristics and genesis of carbonate reservoirs in the Mishrif MB21 member in the Missan oilfield, Iraq [J]. Petroleum Geology \& Experiment, Vol. 38, No 3 May, 2016.

[2] Zhang Yikai; Wang Zhisong; Shi Changlin; et al; Carbonate Reserboir Characteristics and Diagenesis in Missan oilfield, Iraq [J]. Zhang Xuemin; Science Technology and Engineering. Vol. 16, No. 5 Feb, 2016.

[3] Wu Yi; Hou Shaohong; Liu Haihan; Yin Fei. Optimized design of well structure for slim hole drilling in Missan oilfield [J] Journal of Yangtze University (Natural Science Edition) Vol. 12, No. 26 Sep, 2015.

[4] Hou Jie; Liu Yonggui; Li Hai; Aplication of High-Performance Water-Based drilling fluid for horizontal wells tight resrboirs of
Daqing oilfield [J]. Petroleum Drilling Technology, Vol. 43, No. 4 Jul, 2015.

[5] Chen Deming; Liu Huanyu; Dong Dianbin, et al; Lost Cireulatione Control Well AGCS27, Missan Oilfield, Iraq [J], Drilling fluid \& Completion fluid, Vol. 32, No. 2 Mar, 2015.

[6] SHI Bingzhong, HU Xuhui, GAO Shuyang, et al. Visualization sealing simulation test and evaluation of hard brittle shale microfracture [J]. Petroleum Drilling Techniques, 2014, 42 (3): 32-37.

[7] Marin J, Shah F, Serrano M, et al. First Deepwater WellSuccessfully Drilled in Colombia With a High-perform-ance Water-based Fluid. SPE 120768. 2009.

[8] RAMIREZ M A, CLAPPER D K. Aluminum based HPWBM successfully replaces oil based mud to drill exploratory. SPE 94437.

[9] Cathy Hollis, Volker Vahrenkamp, Simon Tull, Abhijit Mookerjee, Conxita Taberner, Yaduo Huang. Pore system characterisation in heterogeneous carbonates: An alternative approach to widely-used rock-typing methodologies [J]. Marine and Petroleum Geology. 2010.

[10] H. Rahimpour-Bonab, H. Mehrabi, A. H. Enayati-Bidgoli, M. Omidvar. Coupled imprints of tropical climate and recurring emergence on reservoir evolution of a mid Cretaceous carbonate ramp, Zagros Basin, southwest Iran [J]. Cretaceous Research, 2012.

[11] Dan Bosence, Kathryn Gibbons, Daniel P. Le Heron, William A. Morgan, Tim Pritchard, Bernard A. Vining. Microbial carbonates in space and time: introduction [J]. Geological Society, London, Special Publications. 2015.

[12] Thomas C. Chidsey, Michael D. Vanden Berg, David E. Eby. Petrography and characterization of microbial carbonates and associated facies from modern Great Salt Lake and Uinta Basin's Eocene Green River Formation in Utah, USA [J]. Geological Society, London, Special Publications. 2015.

[13] Ling HE, Lun ZHAO, Jianxing LI, Ji MA, Ruilin LUI, Shuqin WANG, Wenqi ZHAO. Complex relationship between porosity and permeability of carbonate reservoirs and its controlling factors: A case study of platform facies in Pre-Caspian Basin [J]. Petroleum Exploration and Development Online. 2014.

[14] Shyam Kumar Sharma, Jnan Kachari. Use of KCl-polymer clouding out polyol drilling fluid in combating high pressure in deep exploratory wells of Assam Field: a case study. SPE128849. 2010.

[15] Zhao Wenzhi, Hu Suyun, Liu Wei, Wang Tongshan, Li Yongxin. Petroleum geological features and exploration prospect of deep marine carbonate rocks in China onshore: A further discussion [J]. Natural Gas Industry B. 2014 (1). 